\title{
PARADOXICAL EFFECT OF CORTICOSTEROIDS ON PITUITARY ACTH/B-ENDORPHIN RELEASE IN STRESSED ANIMALS
}

\author{
ELIZABETH A. YOUNG and HUDA AKIL \\ Mental Health Research Institute,University of Michigan, Ann Arbor, Michigan, U.S.A.
}

(Received 17 July 1987; in final form 6 October 1987)

\begin{abstract}
SUMMARY
We have previously demonstrated a number of changes in the anterior lobe proopiomelanocortin (POMC) system in chronically stressed rats. The purpose of the present experiments was to investigate whether chronically stressed rats demonstrate changes in pituitary sensitivity to glucocorticoid negative feedback. To study this question we compared the effects of glucocorticoids on ovine corticotropin releasing factor (oCRF)-stimulated ACTH and B-endorphin release from cell suspensions prepared from naive unhandled rats versus chronically stressed rats. After dexamethasone, there was a 50\% decrease in OCRF-stimulated hormone release in control rats but no inhibition of oCRF-stimulated hormone release in anterior lobe suspension from chronically stressed rats. Rather, the chronically stressed group exhibited a $50 \%$ hormone increase above the oCRF-stimulated baseline. The same pattern was observed after the addition of corticosterone to the medium. These findings suggest that there may be a positive feedback effect of glucocorticoids at the pituitary level under some conditIons of chronic stress.
\end{abstract}

\section{INTRODUCTION}

USING a chronic footshock stress model, we have demonstrated a number of changes in anterior lobe proopiomelanocortin (POMC) regulation. Following two weeks of $\mathbf{3 0}$ min daily footshock, there is an increase in mRNA for POMC (Shiomi et al., 1986), a two-fold increase in POMC content (Young \& Akil, 1985), and changes in the rate of biosynthesis and of post-translational processing of POMC to its end products. We observed no evidence of a subsensitive response to oCRF challenge in short-term anterior lobe suspensions from these chronically stressed animals; in fact, there was an increased sensitivity to CRF-stimulated B-endorphin release in anterior lobe suspensions from chronically stressed animals which were restressed prior to decapitation. Since a number of changes have been demonstrated in anterior lobe regulation of $B$-endorphin biosynthesis and release, it was of interest to test whether these animals demonstrated normal glucocorticoid inhibition of oCRF-stimulated hormone release from the pituitary. To evaluate

Correspondence to be addressed to: Dr. Elizabeth A. Young, Mental Health Research Institute, University of Michigan, 205 Washtenaw Place, Ann Arbor MI 48109-0720, USA. 
this feedback, we compared the effects of glucocorticoids on oCRF-stimulated hormone release in short-term anterior lobe suspensions from control and chronically stressed rats.

\section{METHODS}

Two groups of rats were used. A control group consisted of animals which were unstressed and unhandled. A "chronic stress plus rest" (CS/R) group was exposed to the footshock stressor as previously described (Young \& Akil, 1985) for 30 min daily for 14 days and then was allowed to rest for $24 \mathrm{hr}$. These two groups had similar plasma B-endorphin, ACTH and corticosterone concentrations at the time of decapitation. In addition, short-term anterior lobe suspensions from these animals showed the same response to oCRF (Young \& Akil, 1985).

In order to study $\mathrm{ACTH} / \mathrm{B}$-endorphin release, anterior lobe cell suspensions were prepared from these animals immediately following sacrifice. The methods for dispersing the cells and incubating them have been described previously (Young \& Akil, 1985). In brief, pituitaries were dissected into anterior and neurointermediate lobe. The anterior lobes from two animals were pooled and incubated with collagenase ( $3 \mathrm{mg} / \mathrm{ml}$ ) in Krebs Ringer bicarbonate to dissociate the cells. The cells were washed three times and incubated in Krebs Ringer bicarbonate at $37^{\circ} \mathrm{C}$ under $95 \% 0_{2}: 5 \% \mathrm{CO}_{2}$ for $90 \mathrm{~min}$ to stabilize the cells. The cells were centrifuged, fresh medium was added, and aliquots of each preparation were incubated with either medium alone, dexamethasone $(50 \mathrm{nM})$ alone, oCRF $(0.1 \mathrm{nM})$ alone, or a combination of oCRF and dexamethasone, under $95 \% 0_{2}: 5 \% \mathrm{CO}_{2}$ at $37^{\circ} \mathrm{C}$. Following 60-min incubation, the medium was collected, acidified to $\mathrm{pH} 3.0$, and subsequently extracted with Sep Pak $\mathrm{C}_{18}$ cartridges prior to radioimmunoassay (RIA) for B-endorphin immunoreactivity. For each experiment, two anterior lobes were pooled. Eight anterior lobe suspensions were studied per group.

The B-endorphin antibody, Brenda, was used at a final dilution of 1:40,000. This antiserum recognizes $B-$ endorphin and B-lipotropin equally well when ${ }^{125} \mathrm{I}$ B-endorphin is used as a radiolabeled tracer (Cahill et al., 1983). Each sample was radioimmunoassayed for B-endorphin three times, and the mean values were used to calculate baseline and release. Stimulated release was calculated as total B-endorphin immunoreactivity minus baseline $B$-endorphin immunoreactivity. The intra-assay variability for the $B$-endorphin RIA was $7 \%$, and the inter-assay variability ranged between $10 \%$ and $20 \%$.

Each sample was also radioimmunoassayed for ACTH with the ACTH assay described previously (Young \& Akil, 1985). The ACTH antibody was raised against ACTH 11-24 and was used at a final dilution of 1:80,000. Synthetic human ACTH 1-39 was used as the standard and radiolabeled tracer. The intra-assay variability for the ACTH RIA was 5\%, and the inter-assay variability for ACTH ranged between 10 and $30 \%$. The ACTH and B-endorphin data showed the same pattern, with similar percent stimulation by oCRF and similar percent suppression by dexamethasone. However, because ACTH was assayed only once, there was more variability in ACTH across samples. Therefore, we report only the B-endorphin values.

oCRF was obtained from Bachem (Torrance, $\mathrm{CA}$ ) and was dissolved in a solution of $0.9 \% \mathrm{NaCl}$ with $0.1 \%$ BSA (Fraction V, Sigma) and $0.01 \%$ ascorbic acid (oCRF diluent) added. Dexamethasone sodium phosphate solution (Decadron, Merck, Sharp and Dohme) was obtained at a concentration of $24 \mathrm{mg} / \mathrm{ml}$ from the hospital pharmacy and diluted in oCRF diluent. Corticosterone was obtained from Sigma (St. Louis, MO), dissolved at a concentration of $2 \mathrm{mg} / \mathrm{ml}$ in $100 \%$ ethanol, and diluted in oCRF diluent to the appropriate concentration.

The effects of dexamethasone and corticosterone on OCRF-stimulated release (total release minus baseline release) were compared by two-way analysis of variance (ANOVA). Because the data were not normally distributed, all values were log transformed prior to the ANOVA.

\section{RESULTS}

In cell suspensions from control rats, with 10-10 $\mathrm{M}$ oCRF as a secretagogue, an approximately two-fold increase in B-endorphin in the medium was observed. The data are expressed as percent of unstimulated baseline. When control and chronic stress rest groups were compared, there were no differences in baseline hormone release or oCRF-stimulated release between groups. Dexamethasone had no effect on baseline (unstimulated) release in control or chronic stress cultures. Dexamethasone $(50 \mathrm{nM})$ produced a $40 \%$ inhibition of oCRF-stimulated hormone release in control cell suspensions (Fig. 1). In contrast, in cell suspensions from chronically stressed rats, dexamethasone induced a $50 \%$ increase above the 


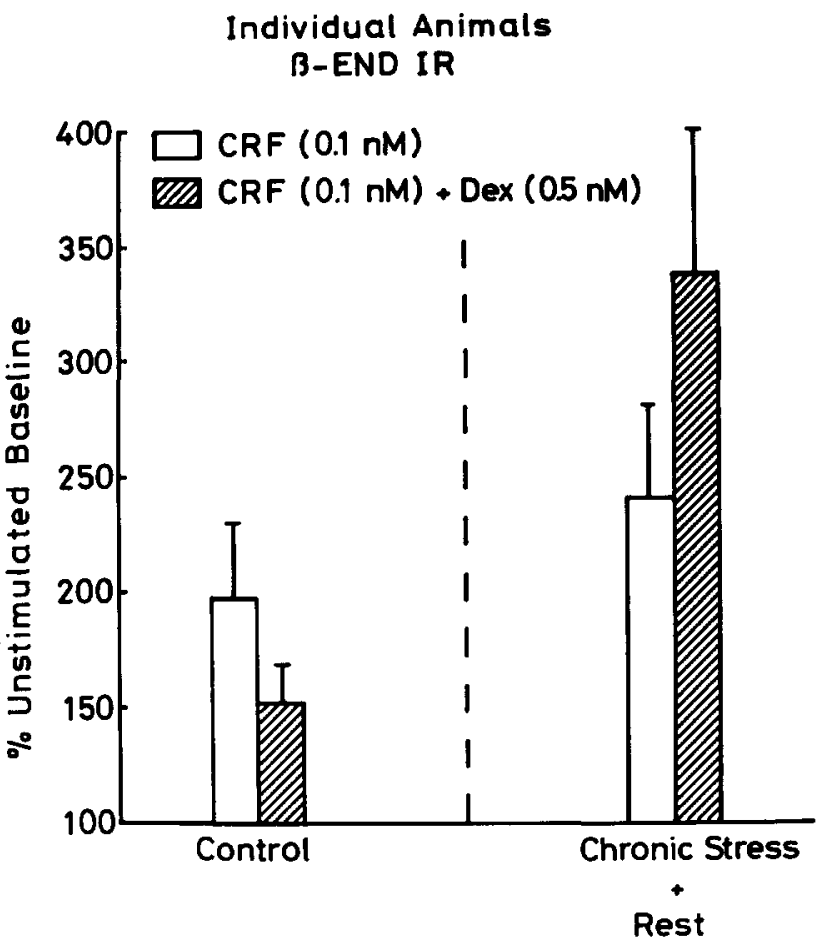

FIG. 1: The effect of dexamethasone (50 nM) on oCRF-stimulated B-endorphin release in pituitary cell suspensions from control and chronically stressed rats (eight rats per group, two rats per suspension). Values are expressed as per cent oCRF-stimulated hormone release. There is no difference between groups in either unstimulated baseline hormone release or in OCRF stimulated release (total release minus baseline). In control cell suspensions from stressed rats, dexamethasone produced a $50 \%$ decrease in oCRF stimulated release (suppression). In contrast, dexamethasone produced an approximately 50\% increase in oCRF-stimulated release in pituitary cell suspensions from chronically stressed rats (potentiation).

oCRF-stimulated baseline (Fig. 1). There also was a significant interaction between stress and dexamethasone $(\mathrm{F}=4.54 ; \mathrm{df}=1,32 ; \mathrm{p}<.04)$. We have found this same stimulatory effect of dexamethasone at $1 \mathrm{nM}$ oCRF in pooled pituitary suspensions from chronically stressed rats. However, since we do not have data from individual animals and therefore have no estimate of variance, we cannot state that this effect is significant at the $1 \mathrm{nM}$ dose of oCRF.

Because dexamethasone, a synthetic steroid, has properties somewhat different from those of naturally occurring glucocorticoids, including a preference for type II glucocorticoid receptors and a lack of binding to corticosteroid binding globulin (CBG) (De Kloet \& McEwen, 1976), we next examined the effect of corticosterone, the predominant naturally occurring glucocorticoid in rats, on oCRF-stimulated B-endorphin release in cell suspensions from control and chronically stressed animals (Fig. 2). The dose of corticosterone was $0.2 \mu \mathrm{g} / \mathrm{ml}$ : or $0.5 \mu \mathrm{M}$. In this experiment, the same hormone release pattern occurred: In control cell suspensions, corticosterone inhibited oCRF-stimulated hormone release by about $60 \%$, whereas it stimulated release in cell suspensions from chronically stressed rats. There again was a significant steroidstress interaction $(\mathrm{F}=5.82, \mathrm{df}=1.58, \mathrm{p}<.02)$. 


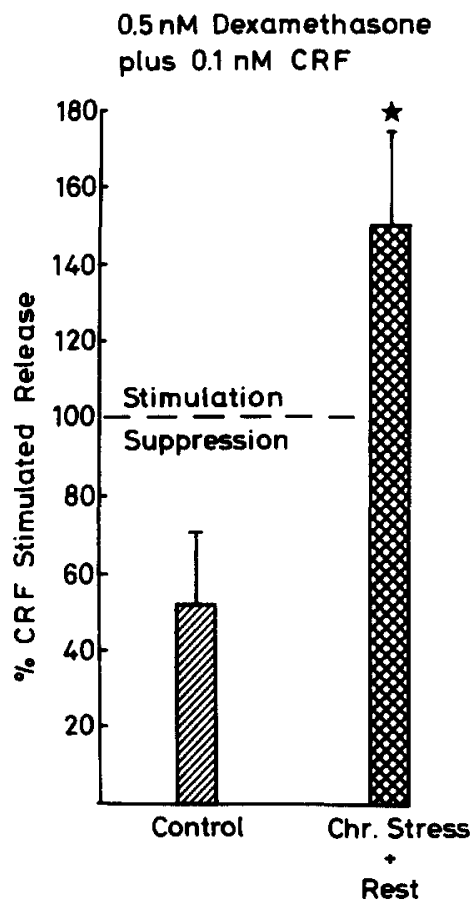

$0.2 \mathrm{vg} / \mathrm{ml}$ Corticosterone plus $0.1 \mathrm{nM}$ CRF



FIG. 2: Comparison of the effect of dexamethasone $(50 \mathrm{nM})$ and corticosterone $(500 \mathrm{nM})$ on CRF-stimulated Bendorphin release in anterior pituitary suspensions from control or chronically stressed rats. Because the steroids affected only stimulated release and not basal secretion, steroid effects are expressed as percent of CRF-stimulated hormone release for each cell suspension. In control anterior pituitary suspensions from unstressed rats, both dexamethasone and corticosterone produced a 50\% decrease in CRF-stimulated hormone release (suppression). In contrast, dexamethasone and corticosterone produced an increase in CRF-stimulated release in anterior pituitary cell suspensions from chronically stressed rats $(42 \%$ increase for dexamethasone, $55 \%$ increase for corticosterone). Pituitary cells from chronically stressed rats showed a significantly different response to steroids compared to the response of cells from normal rats.

\section{DISCUSSION}

The hypothalamo-pituitary adrenal cortical (HPA) axis was long regarded as showing little adaptation to chronic stress. However newer evidence no longer supports this view, particularly for the pituitary. The pituitary content of ACTH and B-endorphin increases dramatically with adrenalectomy (Bimberg et al., 1983) and chronic footshock (Young \& Akil, 1985). The increased hormone content with chronic footshock does not appear to be accompanied by decreased sensitivity to oCRF; in fact, there appears to be an increase in sensitivity to this releasing factor in animals which are restressed before decapitation. The current data suggest that these animals have abnormal glucocorticoid feedback at the anterior pituitary. Because we did not test other doses of dexamethasone or corticosterone, it is possible that higher doses of steroids would have demonstrated normal suppression of B-endorphin in the anterior lobe suspensions from chronically stressed rats. However, the doses used in this study achieved tissue concentrations similar to those in studies demonstrating positive feedback in man (Fehm et al., 1977; 1979; Carey, 1980; Carr et al., 1984). 
Two possible explanations to account for the changes in hormone release in anterior lobe suspensions from chronically stressed rats are: an increase in CRF receptor number and/or a decrease in glucocorticoid receptor number. The identical response to oCRF stimulation in control and chronic stress/rest anterior lobe suspensions (Fig. 1; Young \& Akil, 1985) suggests that changes in CRF receptor number would not explain the increased response to oCRF plus glucocorticoids in these suspensions. Previous reports of increased CRF stimulation, adrenalectomy (Wynn et al., 1985), and chronic stress (Hauger et al., 1986) have indicated decreases in CRF receptors rather than increases. The evidence for pituitary glucocorticoid receptor down-regulation is also unclear.

Pituitary steroid receptor numbers have been shown to increase in vivo after adrenalectomy and to decrease in vitro in cultures continuously exposed to corticosteroids in the medium (Svec \& Rudis, 1981). Demonstration of pituitary steroid receptor down-regulation in vivo has been more difficult. Using a number of daily stressors as well as daily injections with corticosterone in a long acting preparation, Sapolsky et al. (1984) have shown a decrease in steroid receptor numbers in several brain regions, but no changes in the number of pituitary steroid receptors. Certainly, the footshock-endured increase in corticosterone in this stress paradigm is of a smaller magnitude than that of the chronic corticosterone injection paradigm.

However, a change in steroid receptor number is not necessary to explain our finding. Nor is it clear that these effects are mediated by the classic glucocorticoid receptor. Schwartz et al. (1986) have shown that glucocorticoids appear to bind directly to the CRF receptor, and Childs et al. (1986) have shown that glucocorticoids can directly affect CRF receptor number. It is quite possible that the effects of either antagonism or potentiation of CRF-stimulated hormone release in vitro are mediated through a non-glucocorticoid receptor mechanism. The potentiation of oCRF-stimulated hormone release can be explained by a positive feedback mechanism in the pituitary for glucocorticoids. Such positive feedback effects of glucocorticoids have been reported in patients with Cushing's disease and severe depression (James et al., 1965; Krieger et al., 1975; Fehm et al., 1977; 1979; Carey, 1980; Carr et al., 1984). In other systems, such as the gonadal steroid system, positive feedback effects of sex steroid hormones have been noted (Yamaji et al., 1971; Nakai et al., 1978). Likewise, the effects of glucocorticoids are not always the same at different levels of the HPA axis. Mahmoud et al. (1984) reported that 11-deoxycorticosterone or 11-deoxycortisol can antagonize the negative feedback effect of corticosterone fast feedback in intact rats, while these same steroids show negative feedback effects on pituitary ACTH release in vitro in delayed feedback paradigms and in fast feedback studies on brain-lesioned rats. Thus, there is some indication that the positive or negative coupling of different steroids may vary across levels of the HPA axis as well as across experimental conditions and feedback paradigms. If such a change in coupling occurs to elicit positive feedback at the pituitary, then one would not necessarily expect a decrease in steroid receptor number, because such a decrease would lead to a blunted negative feedback response rather than a positive response. Finally, it is possible that a decrease in the classic glucocorticoid inhibitory response leads to an uncovering of an already existing stimulatory effect of glucocorticoids. Our data do not allow us to distinguish between this hypothesis and a "switch" hypothesis. In either case, glucocorticoids can have stimulatory effects at the pituitary. The lack of effect of glucocorticoids alone (in the absence of oCRF) in this experimental paradigm suggests that this stimulatory effect is not a simple one but requires an interaction with oCRF.

We conclude that daily phasic stimulation of the HPA axis can uncover a positive feedback effect of glucocorticoids on the pituitary. This stimulatory effect of steroIds on the pituitary provides a possible explanation for our previously reported paradoxical response to an acute stress in anterior lobe cell suspensions from chronically stressed rats (Young \& Akil, 1985). These studies provide in vitro evidence of a proposed positive feedback loop occurring in 
Cushing's patients and in some patients with endogenous depression (James et al., 1965; Krieger et al., 1975; Fehm et al., 1977; 1979; Carey, 1980; Carr et al., 1984). It is unclear whether this change results from a change in the coupling of the receptor to a second messenger system or from a different and unknown mechanism. Although such changes may seem counter-intuitive in a chronically driven system, they may enable the organism to meet continually the demands imposed by repeated chronic stress without the risk of steroid negative feedback exerting too great a clamp on the system. In addition, they may be coupled to counterbalancing feedback influences at the suprapituitary level, permitting the system to adapt to recurring demands with a different set of regulatory mechanisms. The physiological or environmental events which would foster such mechanisms in vivo need to be explored.

Acknowledgements: We would like to acknowledge the support of ADAMHA grants DA02265 to HA and MH00427 to EY.

\section{REFERENCES}

Bimberg N, Lissitzky JC, Hinman M, Herbert E (1983) Glucocorticoids regulate proopiomelanocortin gene expression in vivo at the levels of transcription and secretion. Proc Natl Acad Sci USA 80: 6982-6986.

Cahill CA, Matthews JD, Akil H (1983) Human plasma beta-endorphin-like peptides: a rapid, high recovery extraction technique and validation of the immunoassay. J Clin Endocrinol Metab 56: 992-997.

Carey RM (1980) Suppression of ACTH by cortisol in dexamethasone non-suppressible Cushing's disease. N Engl J Med 302: 275-279.

Carr DB, Wool C, Lydiard RB, Fisher J, Gelenberg A, Klerman G (1984) Rate sensitive inhibition of ACTH release in depression. Am J Psychiatry 141: 590-592.

Childs GV, Morell JL, Niendorf A, Aguilera G (1986) Cytochemical studies of corticotropin releasing factor (CRF) receptors in anterior lobe corticotrophs: binding, glucocorticoid regulation and endocytosis of [Biotinyl-Ser'] CRF. Endocrinology 119: 2129-2142.

De Kloet ER, McEwen BS (1976) A putative glucocorticoid receptor and a transcortin-like macromolecule in pituitary cytosol. Biochim Biophys Acta 421: 115-123.

Fehm HL, Voigt KH, Lang RE, Beinert KE, Kummer GW, Pfeiffer OF (1977) Paradoxical ACTH response to glucocorticoids in Cushing's disease. N Engl J Med 293: 893-896.

Fehm HL, Voigt KH, Kummer G, Lang R, Pfeiffer OF (1979) Positive rate-sensitive corticosteroid feedback mechanism of ACTH secretion in Cushing's disease. J Clin Invest 64: 102.

Hauger RL, Aguilera G, Milan M, Lorang M, Groves PM (1986) Acute and chronic stress effects on ACTH secretion and anterior pituitary CRF receptors. American College of Neuropsychopharmacology (ACNP) Abstracts, 170.

James VHT, Landon J, Wynn V (1965) Oral and intravenous suppression tests in the diagnosis of Cushing's Syndrome. J Endocrinol 33: 515-524.

Krieger DT, Amorosco L, Linick F (1975) Cyproheptadine induced remission of Cushing's disease. $N$ Engl $J$ Med 293: 893-896.

Mahmoud SN, Scaccianoce S, Scraggs PR, Nicholson SA, Gillham B, Jones MT (1984) Characteristics of corticosteroid inhibition of adrenocorticotropin release from the anterior pituitary gland of the rat. $J$ Endocrinol 102: 33-42.

Nakai Y, Plant TM, Hess DL, Keogh EJ, Knobil E (1978) On the sites of the negative and positive feedback actions of estradiol in the control of gonadotropin secretion in the rhesus monkey. Endocrinology 102: 1008-1014.

Sapolsky RM, Krey LC, McEwen BS (1984) Stress down regulates corticosterone-receptors in a site specific manner in the brain. Endocrinology 114: 287-292.

Schwartz J, Billestrup N, Perrin M, Rivier J, Vale W (1986) Identification of corticotropin releasing factor (CRF) target cells and the effects of dexamethasone on binding in anterior pituitary using a fluorescent analog of CRF. Endocrinology 119: 2376-2382.

Shiomi H, Watson SJ, Kelsey JE, Akil H (1986) Pre-translational and post-translational mechanism for regulating beta-endorphin/ACTH cells: studies in anterior lobe. Endocrinology 119: 1793-1799.

Svec F, Rudis M (1981) Glucocorticoids regulate the receptor in AtT 20 cells. J Biol Chem 256: 5984-5987. 
Wynn PC, Harwood JP, Catty KJ, Aguilera G (1985) Regulation of corticotropin releasing factor (CRF) receptors in rat pituitary gland: effects of adrenalectomy on CRF receptors and corticotroph responses. Endocrinology 116: 1653-1659.

Yamaji T, Dierschke D, Hotchki6s J, Bhattacharga A, Surve A, Knobil F (1971) Estrogen induction of LH release in the rhesus monkey. Endocrinology 89: 1034-1041.

Young EA, Akil H (1985) Corticotropin releasing factor stimulation of adrenocorticotropin and beta-endorphin release: effects of acute and chronic Stress. Endocrinology 117: 23-30. 